Syntax Literate : Jurnal Ilmiah Indonesia p-ISSN: 2541-0849

e-ISSN : 2548-1398

Vol. 5, No. 1 Januari 2020

\title{
HUBUNGAN KECEMASAN DENGAN PENCAPAIAN TARGET KOMPETENSI PRAKTEK KLINIK KEPERAWATAN DASAR MAHASISWA PRODI KEPERAWATAN UPI KAMPUS SUMEDANG
}

\author{
Sri Wulan Lindasari, Reni Nuryani dan Popi Sopiah \\ Universitas Pendidikan Indonesia Kampus Sumedang \\ Email: sriwulan@upi.edu
}

\begin{abstract}
Abstrak
Dalam pendidikan keperawatan banyak metode yang dapat digunakan untuk mencetak perawat agar mempunyai sikap profesionalisme. Salah satu metode pembelajaran keperawatan yang digunakan pada saat mahasiswa dapat melihat pasien secara langsung di lapangan disebut pembelajaran praktek klinik keperawatan. Seringkali mahasiswa keperawatan yang praktik klinik di rumah sakit akan mengalami kecemasan di awal praktik. Penyebab kecemasan antara lain tidak bisa berkomunikasi dengan pasien, tidak bisa melaksanakan tindakan keperawatan, target kompetensi tidak tercapai dan karena baru pertama kali praktek di Rumah Sakit. Selama praktek di Rumah Sakit mahasiswa harus dapat mencapai target kompetensi yang sesuai dengan kurikulum. Dengan adanya kecemasan yang dialami oleh mahasiswa dapat mempengaruhi terhadap pencapaian target kompetensi yang harus dicapai. Penelitian ini bertujuan untuk mengetahui hubungan kecemasan dengan pencapaian target kompetensi dalam praktik klinik keperawatan dasar pada mahasiswa Tingkat II Prodi Keperawatan UPI Kampus Sumedang. Metode yang digunakan dalam penelitian ini adalah dengan deskriptif korelasional. Alat pengumpulan data yang digunakan adalah dengan menggunakan questioner ZSAS untuk kecemasan dan lemar checklist untuk pencapaian target kompetensi. Hasil dari penelitian ini adalah rata-rata tingkat kecemasan pada mahasiswa berada pada kecemasan ringan, rata-rata mahasiswa saat praktek klinik keperawatan dasar menunjukan pencapaian kompetensi baik dan tidak ada hubungan antar kecemasan dengan pencapaian kompetensi dengan nilai sig 0,687. Oleh karena masih adanya mahasiswa yangmengalami kecemasan, disarankan agar dilakukan terapi modalitas untuk mengatasi masalah kecemasan dalam menghadapi praktek klinik keperawatan.
\end{abstract}

Kata kunci: Kecemasan, Target pencapaian Kompetensi, Keperawatan dasar

\section{Pendahuluan}

Pembelajaran praktek klinik keperawatan merupakan salah satu metode yang dapat digunakan untuk mencetak calon perawat agar mempunyai sikap yang profesionalisme dengan cara langsung melihat pasien di lapangan. Pembelajaran klinik dapat memberikan kesempatan kepada mahasiswa untuk dapat menerapkan ilmu yang telah didapatkan selama belajar di akademik kepada situasi nyata dalam memberikan 
pelayanan keperawatan kepada pasien secara langsung sesuai dengan lingkup praktek keperawatan.

Praktek klinik Keperawatan Dasar merupakan praktek klinik yang pertama kali dilakukan oleh mahasiwa selama menempuh pendidikan di D-III keperawatan. Praktek ini memberikan kesempatan pada mahasiswa untuk memberikan asuhan keperawatan pada pasien dalam pemenuhan kebutuhan dasar manusia dengan pendekatan proses keperawatan yaitu melakukan pengkajian, merumuskan diagnose keperawatan, membuat intervensi keperawatan, melakukan tindakan keperawatan dan melakukan evaluasi. Selama praktek ini juga mahasiswa diharuskan untuk dapat mencapai target kompetensi yang sudah ditentukan dalam kurikulum praktek klinik keperawatan dasar.

Pembelajaran praktik klinik merupakan salah satu sumber kecemasan terbesar bagi kalangan mahasiswa keperawatan (Shahsavari, Yekta, Houser, \& Ghiyasvandian, 2013). Berdasarkan hasil penelitian (Rahayuningsih, 2012) sebanyak $62 \%$ mahasiswa mengalami kecemasan sedang dan sebanyak 68\% mengalami cemas ringan selama dalam pembelajaran klinik. Penelitian Pertiwi (2017) diperoleh data bahwa sebanyak 19,2\% mahasiswa merasa cemas dan belum siap untuk praktik di klinik karena belum pernah praktik di rumah sakit sebelumnya. Hal ini sesuai dengan hasil penelitian yang dilakukan (Linawati, 2018) didapatkan hasil bahwa 100\% mahasiswa mengalami kecemasan dalam menghadapi praktek klinik keperawatan dasar.

Penyebab kecemasan antara lain tidak bisa berkomunikasi dengan pasien, tidak bisa melaksanakan tindakan keperawatan, target kompetensi tidak tercapai dan karena baru pertama kali praktek di Rumah Sakit. Dengan adanya kecemasan bisa mengakibatkan berbagai macam reaksi tubuh seperti ada yang susah tidur, otot-otot jadi tegang, nyeri kepala, pusing, badan lemas, sering BAK, dan bahkan sampai konsentrasi mudah teralihkan. Pendapat ini sejalan dengan penelitian (Syahrial, 2018) bahwa terdapat hubungan yang signifikan antara aspek psikologis terhadap ketercapaian kompetensi dimana kompetensi individu akan meningkat dengan adanya peningkatan aspek psikologis yang meliputi persepsi, kepribadian, motivasi, kemampuan belajar dan sikap.

Tujuan dari penelitian ini adalah untuk mengetahui hubungan antara kecemasan dengan pencapaian target kompetensi mahasiswa tingkat II Prodi Keperawatan UPI Kampus Sumedang dalam praktik klinik keperawatan Dasar di Rumah Sakit Umum Kabupaten Sumedang.

\section{Metode Penelitian}

Metode yang digunakan dalam penelitian ini adalah deskriptif korelasional dengan pendekatan cross sectional untuk menjelaskan hubungan antara kecemasan dengan pencapaian keterampilan target kompetensi pada mahasiswa Prodi Keperawatan Universitas Pendidikan Indonesia Kampus Sumedang. Populasi dalam penelitian ini adalah seluruh mahasiswa tingkat II Prodi Keperawatan UPI Kampus Sumedang yang mau lagi praktek klinik keperawatan Dasar sebanyak 139 orang. Sampel yang 
digunakan adalah total Sampling. Penelitian dilakukan pada tanggal 13 Juli-23 Juli 2019 di Prodi Keperawatan UPI Kampus Sumedang. Variabel dependent dalam penelitian ini adalah Pencapaian target kompetensi dan variabel independent nya adalah kecemasan.

Instrumen yang digunakan dalam penelitian ini yang pertama adalah Zung SelfRating Anxiety Scale (ZSAS) untuk mengukur tingkat kecemasan. Instrumen ini terdiri dari 20 pernyataan dan hasilnya digolongkan ke dalam empat tingkatan yaitu nilai 0-20 tidak ada kecemasan, nilai 21-50 cemas ringan, nilai 51-60 cemas sedang dan nilai 6180 cemas berat. Instrumen yang kedua adalah lembar checklist untuk menilai pencapaian target kompetensi keperawatan dasar. Instrumen ini dikembangkan berdasarkan kurikulum yang harus dicapai mahasiswa selama praktek klinik keperawatan dasar dengan jumlah 46 item target kompetensi yang digolongkan kedalam empat tingkatan yaitu kurang dengan nilai $<59$, cukup dengan nilai $60-70$, baik rentang nilai 71-85 dan sangat baik dengan nilai 86-100.

Pada penelitian ini variabel yang dianalisa secara univariat adalah kecemasan dan pencapaian target kompetensi yang dilakukan dengan menggunakan distribusi frekuensi dan proporsi. Analisis bivariate yang digunakan dalam penelitian ini adalah menggunakan Pearson Product Moment.

\section{Hasil dan Pembahasan}

Tabel 1 Hasil Analisis Karakteristik Usia Mahasiswa

\begin{tabular}{ccccc}
\hline Variabel & Mean & Median & SD & Min-Maks \\
\hline Usia & 19,34 & 19 & 0,676 & $18-22$ \\
\hline
\end{tabular}

Berdasarkan tabel 1 menunjukan bahwa 139 mahasiswa yang melakukan praktek klinik keperawatan dasar memiliki rata-rata usia 19,34 tahun dengan rentang usia paling muda berada pada usia 18 tahun dan paling tua pada usia 22 tahun serta median 19 .

Tabel 2 Hasil Analisa Karakteristik Jenis Kelamin Mahasiswa

\begin{tabular}{|c|c|c|}
\hline Variabel & $\mathrm{F}$ & $\%$ \\
\hline \multicolumn{3}{|l|}{ Jenis Kelamin } \\
\hline a. Laki-laki & 30 & 21,6 \\
\hline b. Perempuan & 109 & 78,4 \\
\hline Total & 139 & 100 \\
\hline
\end{tabular}

Berdasarkan tabel bahwa mahasiswa yang mengikuti Praktek Belajar Klinik adalah lebih banyak perempuan $(78,4 \%)$.

Tabel 3 Hasil Analisa Kecemasan Mahasiswa saat Praktek Klinik Keperawatan Dasar

\begin{tabular}{ccccc}
\hline Variabel & Mean & Median & SD & Min-Maks \\
\hline Kecemasan & 36,02 & 36 & 5,77 & $24-54$ \\
\hline
\end{tabular}


Berdasarkan tabel 3 bahwa nilai rata-rata tingkat kecemasan yang terjadi pada mahasiswa saat melakukan praktek klinik keperawatan dasar adalah 36,02 menunjukan tingkat kecemasan ringan, dengan nilai minimal 24 dan maksimal 54.

Tabel 4 Hasil Analisa Pencapaian Kompetensi Mahasiswa saat Praktek Klinik Keperawatan Dasar

\begin{tabular}{ccccc}
\hline Variabel & Mean & Median & SD & Min-Maks \\
\hline Pencapaian & 79,71 & 85 & 16,729 & $39-100$ \\
Kompetensi & & & & \\
\hline
\end{tabular}

Pada tabel 4 berdasarkan rentang pencapaian kompetensi yang telah ditetapkan yaitu bahwa nilai rata-rata mahasiswa saat praktek klinik keperawatan dasar menunjukan pencapaian kompetensi baik dengan skor 79,71 dan nilai minimal 39 serta nilai maksimal 100 .

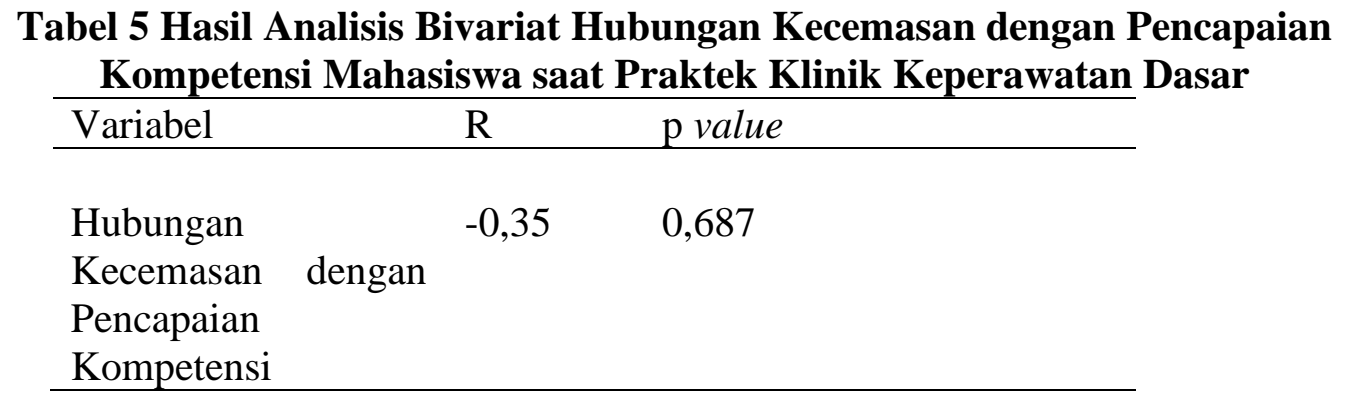

Berdasarkan hasil analisis pada tabel 5 diperoleh nilai sig 0,687 dengan Nilai korelasi Pearson sebesar $-0,35$ yang menunjukan bahwa tidak adanya hubungan antara kecemasan mahasiswa dengan pencapaian kompetensi saat melakukan praktek klinik keperawatan dasar.

Hasil penelitian menunjukkan bahwa usia responden adalah termasuk dalam kelompok usia dewasa awal (18-21 tahun). Proses perkembangan mahasiswa telah memasuki fase dewasa awal yang tidak hanya menuntut untuk meningkatkan kualitas pengetahuan saja, tetapi keterampilan dan kualitas pribadi sebagai bekal hidup mandiri.

Mahasiswa dewasa awal memiliki motivasi untuk belajar lebih tinggi dari pada mahasiswa dewasa tengah karena mahasiswa dewasa tengah mempunyai beban hidup yang lain sehingga perhatiannya tidak hanya untuk belajar. Selain itu, mahasiswa dewasa awal merupakan masa kerja yang produktif. Penelitian Marinki dalam (Sudono, Setya Dhani, Atiningtyas, \& Rif, 2017) menyebutkan bahwa mahasiswa berusia 18-25 tahun berada pada tahap peralihan dari masa perguruan tinggi menuju masa kerja produktif. Selain itu juga usia pada masa dewasa awal terjadi perkembangan intelegensia dan pola pikir yang sudah matang. Dengan bertambahnya usia maka mahasiswa sudah mampu mempersiapkan dirinya dalam menghadapi praktek belajar di klinik. 
Berdasarkan hasil analisis jenis kelamin pada tabel 2 diatas bahwa mahasiswa yang mengikuti Praktek Belajar Klinik adalah lebih banyak perempuan $(78,4 \%)$. Menurut (Sularyo, 2007) bahwa kebutuhan tenaga kesehatan sampai saat ini masih banyak pada perempuan, hal ini berkaitan bahwa perempuan lebih menyayangi dan lebih sabar dalam hal keperawatan termasuk kemampuan dalam praktik klinik di rumah sakit. Pada perempuan masa dewasa awal hampir dua kali lebih mungkin menderita kecemasan dibandingkan dengan laki-laki. Para ahli syaraf menemukan bahwa kepekaan ini dipengaruhi oleh gen, estrogen, progesteron dan fenomena bawaan biologis otak (Brizendine, 2006)

Pada tabel 3 berdasarkan rentang tingkat kecemasan dimana tidak cemas jika nilai 0-20, cemas ringan jika nilai 21-50, cemas sedang jika nilai 51-60 dan cemas berat jika nilai 61-80, bahwa nilai rata-rata tingkat kecemasan yang terjadi pada mahasiswa saat melakukan praktek klinik keperawatan dasar adalah 36,02 menunjukan tingkat kecemasan ringan, dengan nilai minimal 24 dan maksimal 54.

Sebagian besar mahasiswa mengalami kecemasan ringan. Kecemasan ringan ini dapat juga dipengaruhi oleh persiapan mereka sebelum praktek klinik keperawatan dasar. Penelitian (Fidment, 2012) mengatakan bahwa persiapan sebelum praktek klinik di Rumah Sakit merupakan strategi untuk beradaptasi dengan kecemasan yang dialami. Dalam situasi tertentu, kecemasan dapat menjadi pemicu bagi mahasiswa untuk memfokuskan dan menggunakan kemampuan dirinya untuk menghadapi situasi nyata sehingga dengan begitu penampilan mereka akan lebih baik dalam mencapai target kompetensi.

Mahasiswa yang mempersiapkan dirinya dengan baik atau memiliki kompetensi yang baik maka dapat mengurangi kecemasan mahasiswa dalam menghadapi praktek klinik (Putri, 2017). Hal ini sesuai dengan penjelasan (Amir, Iryani, \& Isrona, 2016) bahwa kecemasan pada tingkat ringan justru berefek positif bagi pelajar karena dapat memotivasi belajar serta menghasilkan pertumbuhan dan kreativitas sehingga persiapan dalam ujian akan lebih baik.

Hasil penelitian menunjukkan bahwa sebagian besar nilai untuk pencapaian target kompetensi praktek klinik keperawatan dasar dalam kategori baik $(79,71)$. Hal ini sejalan dengan penelitian (Syahreni \& Waluyanti, 2007) bahwa keberhasilan pembelajaran klinik dipengaruhi oleh kesiapan pengetahuan, mental, emosi dan ketersediaan lingkungan pembelajaran yang kondusif. Dalam semester 3 ini mahasiswa harus siap melakukan praktik klinik keperawatan dasar di rumah sakit meskipun hal ini merupakan pengalaman baru atau pertama kalinya mereka masuk ke Rumah Sakit untuk memberikan asuhan keperawatan langsung berhadapan dengan pasien. Rasa ingin tahu yang besar tentang bagaimana kondisi dan suasana pada saat praktik di rumah sakit ini akan membuat mahasiswa berinisiatif sendiri mencari informasi tentang bagaimana praktik di rumah sakit melalui mahasiswa yang pada tahun sebelumnya. Pada umumnya mahasiswa sangat menyenangi praktik di rumah sakit karena praktik klinik merupakan kegiatan atau pengalaman yang berbeda, mahasiswa bisa mendapatkan pengalaman 
bagaimana mempraktekkan prosedur tindakan keperawatan secara langsung kepada pasien berdasarkan teori dan praktik yang sebelumnya telah dilakukan di laboratorium.

Mahasiswa yang praktik di klinik dan berperan sebagai seorang perawat, akan membentuk motivasi mahasiswa untuk bisa menjalankan pekerjaan sebagai seorang perawat (Pertiwi \& Ermayani, 2017) Salah satu faktor yang mempengaruhi pencapaian target kompetensi adalah motivasi belajar. Dengan motivasi belajar yang baik, penguasaan ilmu pengetahuan keperawatan yang baik, maka mahasiswa akan mencapai target pencapaian kompetensi secara baik (Agustin, 2018) Motivasi belajar akan meningkatkan kesiapan praktek klinik di rumah sakit, artinya motivasi secara individual mempunyai hubungan yang signifikan terhadap kesiapan belajar mahasiswa (Amperiana, 2010). Empat sumber utama dari motivasi intrinsik, yaitu: tantangan, keingintahuan, kontrol dan fantasi (Malloy \& Gambrell, 2012)

Berdasarkan hasil analisis pada table 5 diperoleh nilai sig 0,687 dengan Nilai korelasi Pearson sebesar $-0,35$ yang menunjukan bahwa tidak adanya hubungan antara kecemasan mahasiswa dengan pencapaian kompetensi saat melakukan praktek klinik keperawatan dasar. Kecemasan pada tingkat ringan akan berefek positif bagi mahasiswa karena dapat memotivasi proses pembelajaran dan menghasilkan pertumbuhan dan kreativitas sehingga persiapan dalam praktek belajar klinik akan lebih baik

Hal ini sejalan dengan penelitian (Amir et al., 2016) yang menyatakan bahwa tidak terdapat hubungan yang bermakna antara tingkat kecemasan mahasiswa FK Unand dalam menghadapi OSCE dengan kelulusan OSCE dengan ( $p>0,05$ ). Kecemasan dalam menghadapi praktek klinik keperawatan dasar bukan merupakan salah satu faktor yang memberikan kontribusi terhadap pencapaian target kompetensi mahasiswa. Hal ini sejalan dengan penelitian (Asni \& Sarake, 2013) yang menyatakan bahwa tingkat kecemasan tidak memiliki hubungan dengan hasil OSCE. (Brand \& Schoonheim-Klein, 2009) juga menemukan bahwa tidak ada hubungan yang signifikan antara tingkat kecemasan dengan performa mahasiswa ketika melakukan ujian.

Adanya kepercayaan yang diberikan dari dosen dan tenaga kesehatan kepada mahasiswa akan meningkatkan rasa percaya diri sehingga mahasiswa tidak mengalami kecemasaan saat praktik klinik keperawatan dasar. Praktik klinik diharapkan bukan hanya sekedar kesempatan untuk menerapkan teori yang dipelajari di kelas ke dalam praktik, tetapi diharapkan lebih aktif dalam setiap tindakan sehingga akan menjadi orang yang cekatan dalam melakukan tindakan sesuai dengan teori. Dengan adanya praktek klinik keperawatan dasar ini dapat memberikan kesempatan yang baik untuk dapat melihat secara langsung dan mendapatkan pengalaman penting bagaimana melakukan asuhan keperawatan pada pasien dalam rangka memenuhi kebutuhan dasar manusia. Keberhasilan mahasiswa dalam mengendalikan kecemasan, ini juga dapat meningkatkan rasa kepuasan tersendiri dalam melakukan pelayanan kesehatan bagi pasien. Menurut (Ruliana, 2012) bahwa dalam melakukan praktik di lapangan, perlu bagi seseorang untuk mendapatkan dukungan (Supportiveness), yang berarti dukungan dari lingkungan sekitar baik teman, teman kerja, guru atau atasan 
Semua mahasiswa yang mengikuti praktek klinik keperawatan dasar ini merupakan pengalaman pertama yang mereka ikuti untuk melakukan praktek ke klinik atau rumah sakit. Kecemasan yang dialami beberapa responden merupakan reaksi terhadap suatu hal yang mereka belum pernah alami sebelumnya. Hasil penelitian (Fidment, 2012) melaporkan bahwa tidak ada perbedaan yang signifikan antara mahasiswa yang pertama kali mengikuti OSCE dengan mahasiswa yang pernah mengikuti OSCE sebelumnya. Berdasarkan hal tersebut kekerapan mengikuti OSCE tidak berpengaruh terhadap kecemasan yang dialami responden.

\section{Kesimpulan}

Tingkat kecemasan yang terjadi pada mahasiswa pada saat akan melakukan praktek klinik keperawatan dasar adalah kecemasan ringan. Pencapaian kompetensi mahasiswa pada saat praktek klinik keperawatan dasar menunjukan pencapaian kompetensi baik dengan skor 79,7. Dan tidak adanya hubungan antara kecemasan mahasiswa dengan pencapaian kompetensi saat melakukan praktek klinik keperawatan dasar dengan diperoleh nilai sig 0,687 dengan Nilai korelasi Pearson sebesar -0,35. Oleh karena itu intitusi keperawatan dapat mengalokasikan waktu kepada mahasiswa untuk latihan mandiri, berdiskusi tentang tips sukses menghadapi praktek klinik, dan melakukan terapi untuk menurunkan kecemasan mahasiswa. 


\section{BIBLIOGRAFI}

Agustin, D. (2018). Hubungan Antara Persepsi Dan Minat Belajar Terhadap Mata Pelajaran Kimia Dengan Prestasi Belajar Siswa Kelas XI IPA SMAN 4 Tanjungpinang. Universitas Islam Negeri Sultan Syarif Kasim Riau.

Amir, D. P., Iryani, D., \& Isrona, L. (2016). Hubungan Tingkat Kecemasan dalam Menghadapi Objective Structured Clinical Examination (OSCE) dengan Kelulusan OSCE pada Mahasiswa Fakultas Kedokteran Universitas Andalas. Jurnal Kesehatan Andalas, 5(1).

Amperiana, S. (2010). Pengaruh motivasi, prestasi dan konsep diri Terhadap kesiapan praktek klinik Kebidanan bagi Mahasiswa tingkat ii Akademi kebidanan pamenang Pare Kabupaten Kediri. Universitas Sebelas Maret.

Asni, M., \& Sarake, M. (2013). Faktor yang Berhubungan dengan Penyalahgunaan Narkotika dan Bahan Adiktif (Narkoba) pada Remaja di SMA Kartika Wirabuana XX-1 Makassar Tahun 2013.

Brand, H. S., \& Schoonheim-Klein, M. (2009). Is the OSCE more stressful? Examination anxiety and its consequences in different assessment methods in dental education. European Journal of Dental Education, 13(3), 147-153.

Brizendine, L. (2006). The female brain. Broadway Books.

Fidment, S. (2012). The objective structured clinical exam (OSCE): A qualitative study exploring the healthcare student's experience. Student Engagement and Experience Journal, 1(1), 1-18.

Linawati, L. (2018). Single digit pada pembiayaan Bank BRI Syariah Kantor Cabang Pembantu Ploso Jombang. UIN Sunan Ampel Surabaya.

Malloy, J. A., \& Gambrell, L. B. (2012). Motivation to read. Reading Researchers in Search of Common Ground: The Expert Study Revisited, 154-169.

Pertiwi, G. H., \& Ermayani, M. (2017). The Relationship of Motivation Provision by Clinical Instructor with Student's Readiness to Experience Clinical Practice in Hospital. NurseLine Journal, 2(1), 30-35.

Rahayuningsih, A. (2012). Hubungan Lingkungan Belajar Klinik dengan Tingkat Kecemasan Mahasiswa pada Program Pendidikan Ners. NERS Jurnal Keperawatan, 8(1), 16-23.

Ruliana, D. I. K. A. (2012). Perbedaan Hasil Dan Aktivitas Belajar Siswa Melalui Strategi Pembelajaran Cooperatif Learning Antara Tipe Student Teams Achievement Division (STAD) Dengan Tipe Number Head Toghether (NHT) Pada Siswa Kelas Viii Smp Muhammadiyah 1 Malang Tahun Ajaran 2011/2. University of Muhammadiyah Malang. 
Shahsavari, H., Yekta, Z. P., Houser, M. L., \& Ghiyasvandian, S. (2013). Perceived clinical constraints in the nurse student-instructor interactions: A qualitative study. Nurse Education in Practice, 13(6), 546-552.

Sudiana, H. (2017). Faktor-Faktor Yang Berhubungan Dengan Terjadinya Kecemasan Pada Lanjut Usia Di Panti Wredha Welas Asih. Syntax Literate; Jurnal Ilmiah Indonesia, 2(2), 31-36.

Sudono, B., Setya Dhani, D. S., Atiningtyas, H., \& Rif, A. (2017). Gambaran Kemampuan Berpikir Kritis Perawat Primer Dalam Pelaksanaan Asuhan Keperawatan Di Rumah Sakit Islam Surakarta. Jurnal Ilmu Keperawatan Indonesia, 10(1), 81-82.

Sularyo, T. S. (2007). Buku Ajar I Tumbuh Kembang Anak dan Remaja. Edisi.

Syahreni, E., \& Waluyanti, F. T. (2007). Pengalaman mahasiswa S1 keperawatan program reguler dalam pembelajaran klinik. Jurnal Keperawatan Indonesia, 11(2), $47-53$.

Syahrial, A. S. (2018). Pengaruh Komposisi Warna \& Objek Pendukung Pada Window Display Terhadap Customer Perceived Value Dari Produk Batik Keraton Yogyakarta. Lintas Ruang: Jurnal Pengetahuan Dan Perancangan Desain Interior, 6(1). 